\title{
136. Studies on Screening Test for Lysergic Acid Diethylamide by Test Paper
}

\author{
By Tetsukichi Niwaguchi and Takako InouE \\ National Research Institute of Police Science, Tokyo \\ (Comm. by Tanemoto Furuhata. M. J. A., June 12, 1970)
}

Various analytical methods for lysergic acid diethylamide (LSD) have been reported and some of them are based on a specific coloration of LSD by $p$-dimethylaminobenzaldehyde. Look has suggested a method for field screening test of LSD using this reagent.1)

It is purpose of this paper to establish a method for screening of LSD by test paper.

Experimental. Material. The samples used in this experiment are as follows. LSD, seven kinds of antifebrics and analgesics, eighteen kinds of hypnotics, sixteen kinds of tranquilizers, two kinds of antihistaminics, seven kinds of local anaesthetics, twenty-nine kinds of other drugs, twenty-six kinds of alkaloids and narcotics, and eight kinds of amino acids.

Forms of LSD and drugs used are as follows. LSD: pure powder, tablet containing $50 \mu \mathrm{g}$ of LSD (90\% of lactose, $7 \%$ of starch and $3 \%$ of talc are mixed, ethanol solution containing $50 \mu \mathrm{g}$ of LSD is added, the solvent is evaporated and tablet with $8 \mathrm{~mm}$ in diameter and $2 \mathrm{~mm}$ in thickness is prepared), and sugar cube containing $40 \mu \mathrm{g}$ of LSD (6.3 $\mathrm{g}$ of sugar cube is soaked in ethanol solution containing $40 \mu \mathrm{g}$ of LSD and air-dried).

Drugs: pure powder.

Reagent. 1. Preparation of test paper. Filter paper (Toyo Roshi No. 131) is soaked in a solution of $2 \% p$-dimethylaminobenzaldehyde in ethanol, dried in air and cut into strips for test paper.

2. $2 \%$ sodium hydroxide in methanol.

3. Van Urk reagent. $0.125 \mathrm{~g}$ of $p$-dimethylaminobenzaldehyde is dissolved in $100 \mathrm{ml}$ of $65 \%$ sulfuric acid and $0.1 \mathrm{ml}$ of $5 \%$ ferric chloride is added.

Procedure. 1. Color identification test by test paper. LSD, drugs, alkaloids and amino acids which colored by Van Urk reagent are examined by test paper. A portion of sample is placed on a test paper, a few drops of $2 \%$ sodium hydroxide in methanol is added, air-dried, and a gutta of concentrated hydrochloric acid is dropped. In case of tablet and impregnated sugar cube, a portion of the sample is pulverized, placed on a test paper and examined as mentioned above. 
2. Color identification test by Van Urk reagent. A portion of sample is put into small test tube and approximate $0.5 \mathrm{ml}$ of Van Urk reagent is added.

Result and discussion. Coloration of LSD by test paper.

1. Coloration of LSD pure powder. A gutta of chloroform or ethanol solution of LSD is dropped on test paper, air-dried and a gutta of hydrochloric acid is dropped. Blue-violet color is observed. LSD of more than $0.1 \mu \mathrm{g}$ is detectable. When the test paper is exposed to the vapor of hydrochloric acid instead of dropping concentrated hydrochloric acid, more clear blue-violet color is observed since colored spot does not diffuse.

2. Coloration of LSD tablet. A portion of $97.2 \mathrm{mg}$ of tablet is pulverized and powder obtained is put on test paper. Coloration is examined as follows.

(1) Dropping of hydrochloric acid: A gutta of concentrated hydrochloric acid is dropped to the powder of tablet placed on test paper. Following result is obtained. The numerals in parentheses show amount of LSD in the powder of tablet, on the assumption that $50 \mu \mathrm{g}$ of LSD is uniformly distributed in a tablet.

\begin{tabular}{l|c|c}
\hline \multicolumn{2}{c|}{ Amount of powder } & Coloration \\
\hline $1.7 \mathrm{mg}$ & $(0.9 \mu \mathrm{g})$ & negative \\
$3.7 \mathrm{mg}$ & $(1.9 \mu \mathrm{g})$ & negative \\
\hline
\end{tabular}

(2) Dropping of hydrochloric acid and heating: After dropping of concentrated hydrochloric acid as mentioned above, the test paper is heated with small flame.

\begin{tabular}{l|l|l}
\hline \multicolumn{2}{l|}{ Amount of powder } & Coloration \\
\hline $0.5 \mathrm{mg}$ & $(0.3 \mu \mathrm{g})$ & negative \\
$1.9 \mathrm{mg}$ & $(1.0 \mu \mathrm{g})$ & positive \\
$2.7 \mathrm{mg}$ & $(1.4 \mu \mathrm{g})$ & positive \\
\hline
\end{tabular}

(3) Dropping of $2 \%$ sodium hydroxide in methanol and hydrochloric acid: A few drops of $2 \%$ sodium hydroxide in methanol are added to the powder of tablet placed on test paper, dried in air, and a gutta of concentrated hydrochloric acid is dropped.

\begin{tabular}{l|c|l}
\hline \multicolumn{2}{c|}{ Amount of powder } & Coloration \\
\hline $1.0 \mathrm{mg}$ & $(0.5 \mu \mathrm{g})$ & negative \\
$1.6 \mathrm{mg}$ & $(0.8 \mu \mathrm{g})$ & positive \\
$1.8 \mathrm{mg}$ & $(0.9 \mu \mathrm{g})$ & positive \\
\hline
\end{tabular}


Color reaction of LSD on test paper may be disturbed by binders and diluents in the tablet in case of only dropping hydrochloric acid. Consequently, methanolic alkaline solution is used for being easy to extract LSD or LSD salt onto test paper from the tablet. It is elucidated that method (3) is most suitable for field screening test of LSD in tablet.

3. Coloration of sugar cube impregnated with LSD. A portion of $6.3 \mathrm{~g}$ of sugar cube impregnated with LSD is pulverized and powder obtained is put on test paper. Sodium hydroxide in methanol and hydrochloric acid are added as described in LSD tablet, and coloration is observed. The numerals in parentheses show amount of LSD in the powder of sugar cube, on the assumption that $40 \mu \mathrm{g}$ of LSD is uniformly distributed in a sugar cube.

\begin{tabular}{l|l|l}
\hline \multicolumn{2}{c|}{ Amount of powder } & Coloration \\
\hline $100 \mathrm{mg}$ & $(0.6 \mu \mathrm{g})$ & negative \\
$200 \mathrm{mg}$ & $(1.2 \mu \mathrm{g})$ & negative \\
$300 \mathrm{mg}$ & $(1.9 \mu \mathrm{g})$ & positive \\
\hline
\end{tabular}

Table I. Coloration by Van Urk reagent and test paper

\begin{tabular}{l|l|l}
\hline \multicolumn{1}{c|}{ Compound } & Van Urk rgt. & \multicolumn{1}{c}{ Test paper } \\
\cline { 2 - 3 } Antipyrin & Yellow & Red-orange* \\
Ethinamate & Red-brown & Red-brown* \\
Promazine HCl & Red-orange & Orange* \\
Acetylpromazine maleate & Orange & Yellow-orange \\
Dipacol HCl & Red-orange & Orange \\
Triflupromazine HCl & Yellow-orange & Red-violet* \\
Flumezine maleate & Yellow-orange & Red-violet* \\
Levomepromazine maleate & Blue-violet & Blue-violet \\
Prothipendyl HCl & Yellow & Yellow \\
Pacatal & Red-orange & Orange* \\
Prochloroperazine maleate & Red-violet & Red-violet* \\
Perphenazine HCl & Red-violet & Red-violet \\
Azacyclonal HCl & Red-violet & Red-violet \\
Promethazine HCl & Brown & - \\
Morphine & Yellow-orange & \\
Codeine & Yellow-orange & - \\
Ohton & Dark brown & Blue-violet \\
Ergotamine & Blue-violet & Yellow \\
Scopolamine & Red-violet & Red-violet* \\
Methoxyphenamine HCl & Red-violet & Yellow \\
Lobeline HCl & Yellow & Blue-violet \\
Myricitrin & Blue-violet & \\
Tryptophan & S & \\
\hline
\end{tabular}

*: Discolored to blue-violet in $10 \mathrm{hr}$. 
Volume of methanolic alkaline solution dropped should be minimized to be enough for covering the powder of sugar placed on the test paper, so as not to diffuse LSD extracted on the test paper. It is necessary that methanolic alkaline solution is dried as completely as possible before dropping of concentrated hydrochloric acid.

In any case where LSD is contained more than detectable limit, blue-violet color appears within one minute after dropping of concentrated hydrochloric acid and becomes clear slowly.

Coloration of drugs, alkaloids, and amino acids by Van Urk reagent and by test paper.

Color identification test is examined on various drugs, alkaloids, and amino acids using Van Urk reagent, in order to confirm that the reagent is suitable for screening test of LSD. The results are shown in Table I.

Only three compounds out of the samples examined develop blue-violet color on test paper as same as LSD. They are ergotamine, tryptophane and levomepromazine. Some tranquilizers consisting of phenothiazine derivatives except levomepromazine color to red or red-violet. It is assumed that ergot alkaloids develop same color as LSD.

\section{Reference}

(1 J. Look: J. Pharm. Sci., 56, 1526 (1967). 